\title{
Introduction to the Special Issue on Justice-Related Appraisals and Recovery Outcomes
}

\author{
Michael J L Sullivan ${ }^{1}$
}

Received: 4 January 2016 / Accepted: 5 January 2016 / Published online: 13 January 2016

(C) Springer Science+Business Media New York 2016

The past decade has witnessed a resurgence of interest in the relation between justice-related appraisals and health outcomes (Sullivan, Scott, \& Trost, 2012). An emerging body of research suggests that the greater the degree of loss or suffering consequent to injury, the more likely that an injury will be experienced as a violation of justice principles (Sullivan, Yakobov, Scott, \& Tait, 2014). Findings have also emerged suggesting that justice-related appraisals are likely to trigger a cascade of cognitive, emotional, and behavioral responses that ultimately compromise the recovery process following injury (Sullivan et al., 2014).

Clinical anecdotes abound of persistent pain sufferers who feel they have been unjustly victimized either as a direct result of their injury, or indirectly by the sequellae of their injury (Aceves-Avila, Ferrari, \& Ramos-Remus, 2004; Bigos \& Battie, 1987). Verbalizations such as "I wish he could see what he has done to my life," "What did I do to deserve this?,"or "Nothing will ever make up for what I have gone through," reflect at once elements of the perceived unfairness of suffering, the magnitude of loss consequent to injury, the inadequacy of compensation, and the desire for retribution.

Empirical research on justice-related appraisals has proceeded along several different lines. Studies have examined the buffering effects of just-world beliefs in individuals with chronic pain (McParland, Hezseltine, Serpell, Eccleston, \& Stenner, 2011; McParland, Hezseltine, Serpell, Eccleston, $\&$ Stenner 2011). Other studies have examined the impact of

Michael J L Sullivan

Michael.Sullivan@mcgill.ca

1 Department of Psychology, Medicine and Neurology, Montreal, QC, Canada claimant dissatisfaction with health or employer practices on distress and disability in injured workers (Chibnall, Tait, Andresen, \& Hadler, 2006). Research has also examined the relation between scores on measures of perceived justice and measures of symptom severity and disability (Sullivan, Adams, Martel, Scott, \& Wideman, 2011). Findings have been consistent in showing that justice-related appraisals are significant determinants of symptom severity, emotional distress, and disability consequent to debilitating injury (Sullivan et al., 2008; Sullivan et al., 2012). Despite the apparent centrality of themes of injustice in the experience of and recovery from injury, justice-related appraisals have not been addressed directly within current biopsychosocial models of pain and disability (Gatchel, Peng, Peters, Fuchs, \& Turk, 2007).

Until recently, perceived injustice was not thought to be an important determinant of recovery and rehabilitation outcomes. As a result, the clinical management of perceived injustice in the treatment of individuals with persistent musculoskeletal pain has not been systematically addressed. Indeed, in the subject index of leading cognitive-behavioral treatment manuals for pain and disability management, the word "injustice" does not appear (Kerns, Sellinger, \& Goodin, 2011; Taylor, 2005; D. Turk, Meichenbaum, \& Genest, 1983).

Although justice-related appraisals might be construed as mental constructions, like all mental representations, they can be fueled, at least in part, by objective characteristics of an external reality. It is becoming clear that there are situational and systemic variables that are likely to seed the development of perceptions of injustice. Reckless drivers and unsafe work environments do exist, as do unfair, disrespectful or adversarial insurer practices. Injured individuals might face legitimate and continuing inequities in access to services and resources in medical, insurer, and employment systems. These external forces can lead to the emergence and persistence of perceptions of injustice following injury. 
It has been suggested that justice-related appraisals are distinct from other pain-related psychosocial risk factors with respect to the multiplicity of sources from which they can arise and the range of processes implicated in their impact on recovery outcomes (Sullivan et al., 2014). Personal, social, and systemic influences converge to render justice-related appraisals one of the most challenging pain-related psychosocial risk factors to target clinically (McParland, Eccleston et al., 2011, McParland, Hezseltine et al., 2011; Sullivan et al., 2012; Tait, 2004). Indeed, research suggests that even multidisciplinary approaches to pain and disability management have a negligible impact on perceptions of injustice (Sullivan et al., 2008). Given the magnitude of the disability problem associated with injury, and the expense of adverse recovery outcomes, the development of approaches to prevent the emergence of perceptions of injustice or to reduce perceptions of injustice becomes a priority.

The papers included in this special issue address a broad range of topics related to both the buffering and deleterious effects of justice-related appraisals on recovery outcomes. Although numerous investigations have shown that justicerelated appraisals can lead to heightened pain, emotional distress, and disability, little is known about the sources or determinants of justice-related appraisals and the mechanisms by which justice-related appraisals impact on recovery outcomes. One of the objectives of this special issue was to address some of the knowledge gaps that currently exist about the relation between justice-related appraisals and adverse recovery outcomes.

In the first paper of the special issue, Scott et al. (Scott et al., 2016) address injured claimants' perspectives on the factors that have contributed to their sense of injustice. Workdisabled individuals enrolled in a rehabilitation program were interviewed about the factors that led them to view their injury experience as an injustice. Not surprisingly, identified sources of injustice included the individuals who played a role in the event or situation associated with injury, such as the other driver or the employer. However, even individuals who did not have a direct causative role in the injury were identified as sources of injustice. Insurance representatives, health care providers, and family members were identified as the sources of perceived injustice by a high proportion of claimants.

Scott et al. (Scott et al., 2016) also report that, on average, claimants identified 4 sources of injustice related to their injury, and cited 5 ways in which these sources contributed to their sense of injustice. It is likely that injured individuals reflect not only on the direct causes of their injury, but also on the degree to which others in the post-injury environment have provided the financial resources, treatment or support to which they might have felt entitled. The multitude of sources of perceived injustice following injury highlights the complexity of justice-related appraisals.
In the second paper in the special issue, Tait and Chibnall (Tait \& Chibnall, 2016) report the results of a large prospective cohort study examining the relation between claimant dissatisfaction and progression toward chronic disability. Tait and Chibnall (2016) use dissatisfaction ratings as a proxy for perceptions of injustice. They proceed from a definition put forward by Adams (1965) where injustice is defined as a dissatisfied state of mind emerging from a discrepancy between what is and what should be. Indeed, dissatisfaction might represent a fundamental phenomenological dimension of experience consequent to a justice violation. The results of Tait and Chibnall's study showed that claimants who indicated dissatisfaction with medical care and employer treatment following injury were more likely to become permanently disabled.

McParland and Knussen (McParland \& Knussen, 2016) report the results of analyses examining the role of catastrophizing in the relation between just - world beliefs and pain outcomes. The authors first review literature addressing the "buffering" effects of just-world beliefs. They note that believing that one's world is just appears to confer benefit in the form of less intense pain, distress, and disability. The authors report that when catastrophizing is statistically controlled, the relation between just world beliefs and pain outcomes is no longer significant.

McParland and Knussen (2016) suggest two possible routes by which catastrophizing might influence the relation between just-world beliefs and pain outcomes. First, they suggest that having a weak belief in a just world might leave an individual more susceptible to interpreting his or her health condition as catastrophic, in turn, augmenting symptom severity. Alternately, they suggest that a strong belief in a just world might protect against the initiation of catastrophic interpretations, in turn, attenuating symptom severity.

Trost and her colleagues (Trost, Minden, Buelow, Boals, \& Scott, 2016) present the results of a study examining the relation between perceptions of injustice and intention to litigate in individuals with spinal cord injuries. Their findings showed that high scores on a measure of perceived injustice predicted greater external attribution of responsibility, less forgiveness, and greater intention to litigate.

The findings of Trost et al. (2016) provide the first evidence of a relation between perceptions of injustice and intent to litigate. Given the abundance of research pointing to the deleterious effects of litigation on recovery trajectories, these findings suggest that litigation might be one of the pathways through which perceptions of injustice exert their negative impact on recovery outcomes. To the extent that intention to litigate can be construed as form of retribution, the findings of Trost et al. (2016) are also the first to empirically demonstrate that retribution motives can be elicited by post-injury perceptions of injustice. 
In the fifth paper of the special issue, Yakobov et al. (Yakobov, Scott, Thibault, \& Sullivan, 2016) examine how treatment-related reductions in suffering and losses are associated with reductions in perceived injustice. In their study, Yakobov et al. (2016) use symptom severity as a proxy for injury-related suffering and use severity of disability as a proxy for injury-related losses. The results of their analyses revealed that reductions in disability were the strongest predictor of reductions in perceived injustice.

There are important treatment implications to the findings of Yakobov et al. (2016). Treatment focus, particularly in primary care, tends to be on symptom reduction as opposed to disability reduction. The findings of Yakobov et al. (2016) suggest that treatment techniques specifically designed to reduce disability might need to be considered if reductions in perceived injustice are to be achieved.

The last paper in this special issue describes the psychometric properties of a brief instrument to assess perceptions of injustice associated with debilitating health and mental health conditions (Sullivan, Adams, Yakobov, Ellis, \& Thibault, 2016). The authors note that while the Injustice Experiences Questionnaire (IEQ; (Sullivan et al., 2008) has been an important tool to study the influence of perceived injustice on recovery outcomes, the instructional set of the IEQ is worded specifically in relation to the consequences of injury. The authors argue that modifying the IEQ in a manner that would permit its use across a wide range of debilitating health and mental health conditions could have important conceptual and clinical implications.

Sullivan et al. (2016) describe the item content and psychometric properties of the Injury Experiences QuestionnaireShort Form. The authors report that the IEQ-SF has good reliability and validity whether used to assess perceived injustice in individuals with a musculoskeletal condition or individuals with a mental health condition. A finding of interest is that individuals with a depressive condition scored higher on the IEQ-SF than individuals with a pain condition. The authors suggest that a measure of perceived injustice permitting cross-disability comparisons might provide useful insights into the ontology of perceived injustice and the mechanisms by which perceived injustice adversely affects health and mental health outcomes.

\section{Clinical Implications}

As noted earlier, research conducted to date suggests that perceived injustice is one of the strongest predictors of adverse recovery outcomes, and it is the psychosocial risk factor least likely to respond to current approaches to the management of pain-related disability in individuals who have sustained debilitating injuries. The effective treatment or management of perceived injustice in individuals with debilitating health or mental health conditions will require knowledge about the sources of perceived injustice, and the processes by which perceptions of injustice influence recovery trajectories.

The findings of the papers included in the special issue have provided some insights into potential avenues of intervention that might prevent or reduce perceptions of injustice associated with debilitating health or mental health conditions. The paper by Scott et al. (2016) revealed that injured individuals identify a host of sources of their sense of injustice. Interventions designed to target perceptions of injustice are likely to vary as a function of the sources of perceived injustice. For example, interventions designed to target perceptions of injustice are likely to differ as a function whether the individuals' perceptions of injustice are being fueled by adversarial interactions with the insurer as opposed to invalidating responses from family members.

The paper by McParland and Knussen (2016) suggests that interventions designed to reduce catastrophic thinking might help reduce perceptions of injustice. The findings of Yakobov et al. (2016) suggest that interventions that are designed to reduce disability might also yield reductions in perceptions of injustice. In the discussion section of various papers, authors also make suggestions about techniques that might be considered in interventions designed to reduce perceptions of injustice. These include validation techniques, forgiveness-focused techniques, and acceptance techniques. The findings of Sullivan et al. (2016) suggest that intervention approaches that combine several risk-targeted techniques have the potential for yielding clinically meaningful reductions in perceptions of injustice.

Several authors also addressed the need to consider prevention strategies in the management of perceived injustice. If research reveals that perceptions of injustice are sometimes fueled by ongoing justice violations such as disrespectful or adversarial interactions with insurers or health professionals, then it might be possible to change policy, practice patterns, or interactional styles in a manner that will reduce the probability that perceptions of injustice will emerge. In other words, optimal management of perceived injustice might require interventions addressing both the injured individual's injustice appraisals as well as the sources of perceived injustice. The research on the determinants of justice-related appraisals holds promise of providing the empirical foundation for the development of interventions that might contribute to more successful recovery outcomes following the onset of a debilitating health or mental health condition.

\section{Theoretical Implications}

Biopsychosocial conceptualizations of pain experience and pain-related outcomes have played a significant role in drawing attention to the complex interplay among physical, psychological, and social factors that contribute to pain-related disability. However, the predictive utility of these models has 
been limited by the dearth of evidence specifying the relations that govern the influence of various model components on health and mental health outcomes. Furthermore, current biopsychosocial models of pain and disability following injury have been silent about the role of perceived injustice on recovery outcomes (Nieto, Miro, \& Huguet, 2009; D. C. Turk, 2002; Vangronsveld, Peters, Goossens, Linton, \& Vlaeyen, 2007).

A comprehensive biopsychosocial model of pain and disability will require greater consideration of the role of perceived injustice in the experience of pain and associated disability. Blame and retribution are concepts that have been discussed in theoretical models of organizational and retributive justice, yet none of these models has been elaborated with sufficient precision to generate specific hypotheses in the context of disabling injury or illness (Darley \& Pittman, 2003; Lerner, 1980; McParland \& Eccleston, 2013). There remain many unanswered questions about how perceptions of injustice emerge, when they emerge, the fundamental characteristics of events, situations, or interaction that influence their development or persistence, the processes by which they impact on health or mental health outcomes, and the nature of intervention strategies that will be required to effectively target perceptions of injustice in treatment. These are questions that will need to be addressed in future research.

Although research on the psychology of justice-related appraisals following injury remains in its infancy, concepts of justice have been addressed in other domains of psychological and behavioral research for several decades. Sizeable literatures exist on concepts related to justice-related beliefs, forgiveness, blame, and revenge/retribution. Ostensibly, there is a set of underlying principles that ties these divergent bodies of literature together. Yet, at present, no overarching model has been put forward to guide study questions or the interpretation of findings. As a result, research has moved forward in a piecemeal fashion. Meaningful advance in this area of research and practice will depend to some degree on the development of a unifying conceptual framework that brings together divergent lines of research that address the development, functions, and consequences of justice-related appraisals.

\section{Compliance with ethical standards}

Conflict of interest The author declares that he has no competing interests. This research was supported by funds from the Canadian Institutes for Health Research.

\section{References}

Aceves-Avila, F. J., Ferrari, R., \& Ramos-Remus, C. (2004). New insights into culture driven disorders. Best Practices and Research in Clinical Rheumatology, 18, 155-171.
Adams, J. S. (1965). Inequity in social exchange. In L. Berkowitz (Ed.), Advances in experimental social psychology, 9. New York: Academic.

Bigos, S. J., \& Battie, M. C. (1987). Acute care to prevent back disability. Clinical Orthopedics and Related Research, 221, 212-230.

Chibnall, J. T., Tait, R. C., Andresen, E. M., \& Hadler, N. M. (2006). Clinical and social predictors of application for social security disability insurance by workers' compensation claimants with low back pain. Journal of Occupational and Environmental Medicine, 48(7), 733-740.

Darley, J. M., \& Pittman, T. S. (2003). The psychology of compensatory and retributive justice. Personality and Social Psychology Review, 7, 324-336.

Gatchel, R. J., Peng, Y. B., Peters, M. L., Fuchs, P. N., \& Turk, D. C. (2007). The biopsychosocial approach to chronic pain: scientific advances and future directions. Psychological bulletin, 133, 581-624.

Kerns, R. D., Sellinger, J., \& Goodin, B. R. (2011). Psychological treatment of chronic pain. Annual Review of Clinical Psychology, 7, 411-434.

Lerner, M. J. (1980). The belief in a just world: a fundamental delusion. New York: Plenum.

McParland, J. L., \& Eccleston, C. (2013). "it's not fair": social justice appraisals in the context of chronic pain. Current Directions in Psychological Science, 22, 484-489.

McParland, J. L., Eccleston, C., Osborn, M., \& Hezseltine, L. (2011a). It's not fair: an interpretative phenomenological analysis of discourses of justice and fairness in chronic pain. Health (London), 15(5), 459-474.

McParland, J. L., Hezseltine, L., Serpell, M., Eccleston, C., \& Stenner, P. (2011b). An investigation of constructions of justice and injustice in chronic pain: a Q-methodology approach. Journal of Health Psychology, 16(6), 873-883.

McParland, J. L., \& Knussen, C. (2016). Catastrophizing mediates the relationship between personal belief in a just world and pain outcomes among chronic pain support group attendees. Psychological Injury and Law, 9.

Nieto, R., Miro, J., \& Huguet, A. (2009). The fear-avoidance model in whiplash injuries. European Journal of Pain, 13(5), 518-523.

Scott, W., McEvoy, A., Garland, R., Bernier, E., Milioto, M., Trost, Z., \& Sullivan, M. J. L. (2016). Sources of injustice among individuals with persistent pain following musculoskeletal injury. Psychological Injury and Law, 9.

Sullivan, M. J. L., Adams, H., Horan, S., Maher, D., Boland, D., \& Gross, R. (2008). The role of perceived injustice in the experience of chronic pain and disability: scale development and validation. Journal of Occupational Rehabilitation, 18(3), 249-261.

Sullivan, M. J. L., Adams, H., Martel, M. O., Scott, W., \& Wideman, T. (2011). Catastrophizing and perceived injustice: risk factors for the transition to chronicity after whiplash injury. Spine, 36(25 Suppl), S244-S249.

Sullivan, M. J. L., Adams, H., Yakobov, E., Ellis, T., \& Thibault, P. (2016). Psychometric properties of a brief instrument to assess perceptions of injustice associated with debilitating health and mental health conditions. Psychological Injury and Law, 9.

Sullivan, M. J. L., Scott, W., \& Trost, Z. (2012). Perceived injustice: a risk factor for problematic pain outcomes. The Clinical Journal of Pain, 28(6), 484-488.

Sullivan, M. J. L., Yakobov, E., Scott, W., \& Tait, R. C. (2014). Perceived injustice and adverse recovery outcomes. Psychological Injury and Law, 7, 325-334.

Tait, R. C. (2004). Compensation claims for chronic pain: effects on evaluation and treatment. In R. H. Dworkin \& W. Breitbart (Eds.), Psychosocial aspects of pain: a handbook for health care providers. Seattle, WA: IASP Press.

Tait, R. C., \& Chibnall, J. T. (2016). Workers' compensation claimants with low back pain: The role of dissatisfaction in the transition to disability. Psychological Injury and Law, 9. 
Taylor, R. R. (2005). Cognitive behavioral therapy for chronic illness and disability. New York: Springer.

Trost, Z., Minden, K. R., Buelow, M., Boals, A., \& Scott, W. (2016). Perceived injustice predicts intention to litigate: findings from a spinal cord injury sample. Psychological Injury and Law.

Turk, D. C. (2002). A diathesis-stress model of chronic pain and disability following traumatic injury. Pain Research \& Management, 7(1), 9-19.
Turk, D., Meichenbaum, D., \& Genest, M. (1983). Pain and behavioral medicine: a cognitive-behavioral perspective. New York: Guilford.

Vangronsveld, K., Peters, M., Goossens, M., Linton, S., \& Vlaeyen, J. (2007). Applying the fear-avoidance model to the chronic whiplash syndrome. Pain, 131(3), 258-261.

Yakobov, E., Scott, W., Thibault, P., \& Sullivan, M. J. L. (2016). Treatment-related reductions in disability are associated with reductions in perceived injustice following whiplash injury. Psychological Injury and Law, 9. 